\title{
A 20-YEAR STUDY OF WINTERING COMMON CRANE FLUCTUATIONS USING TIME SERIES ANALYSIS
}

LUIS M. BAUTISTA, Museo Nacional de Ciencias Naturales, CSIC, 28006 Madrid, Spain

JUAN C. ALONSO, Museo Nacional de Ciencias Naturales, CSIC, 28006 Madrid, Spain

JAVIER A. ALONSO, Departamento de Biología Animal, Facultad de Biología, Universidad Complutense, 28040 Madrid, Spain

\begin{abstract}
The numbers of common cranes (Grus grus) staging and wintering at Laguna de Gallocanta (Gallocanta), northeastern Spain, have increased throughout the period 1970-90. Consequently, we modelled the use of this area by cranes using Box-Jenkins Time Series Analysis to evaluate the influence of local food availability, duck hunting, and habitat and food conditions at other more traditional crane wintering areas in southwestern Spain on Gallocanta crane numbers. Food availability was not correlated with crane numbers at Gallocanta except during mid-winter. However, restrictions on duck hunting in 1973 and its total prohibition in 1981 correlated with increased crane numbers, and probably provided the most immediate reason for this increase. Habitat and food conditions at other wintering areas had no apparent influence upon crane numbers at Gallocanta. Because annual productivity figures were not correlated with the observed increase, we suggest that a northward shift in the wintering range associated with food provided by agriculture, together. with a possible decline in mortality due to legal protection along the species' migratory route, probably have been major long-term factors contributing to the increase in cranes wintering at Gallocanta.
\end{abstract}

J. WILDL. MANAGE. 56(3):563-572

The use of an area by a species depends on the possibilities of meeting all requirements necessary for survival. Particularly among certain migratory bird species, the use of stopover and wintering areas may be strongly influenced by human-induced habitat changes. These are especially relevant for granivorous and herbivorous bird species, many of which have adapted rapidly to exploit food resources offered in agricultural areas (Wiens and Johnston 1977, Ebbinge 1985, Edwards et al. 1989, Inglis et al. 1990, Owen 1990). The common crane is such a species, with behavioral preadaptations to respond quickly to habitat changes, either natural or induced by man. Mobility and gregariousness have enabled this and other crane species to exploit new food sources provided by farming activities (Krapu et al. 1984, Tacha et al. 1984, Sugden et al. 1988). Since the mid-1970's, the area of Gallocanta in northeastern Spain increasingly has been used by European common cranes as a staging and wintering area (Alonso et al. 1987). Among the possible non-exclusive factors responsible for this increase are: an increase in food availability in the local area; enhanced protection of the area; a loss of habitat or a decrease in food availability at other wintering areas; an increase in the size of the species' population in Western Europe; and/or a migration shift from the eastern to the western migratory routes. Herein, we analyze a 20 -year time series of data on use of Gallocanta by cranes.
Our objective was to identify and quantify the factors determining fluctuations in crane numbers staging in our study area. We chose to use Box-Jenkins Time Series Analysis (Box and Jenkins 1976), a reliable technique to detect and study changes in ecological time series that enables a more objective interpretation of the relative importance of different causal factors (Jassby and Powell 1990).

We are very grateful to the many people that cooperated in surveying cranes in and outside our study area. We also thank J. H. Bernat and D. Peña for statistical advice and G. L. Krapu and D. H. Johnson for a critical reading of the manuscript. This is a contribution to Project PB87-0389 of the Dirección General de Investigación Científica y Técnica.

\section{STUDY AREA}

The area of Gallocanta $\left(40^{\circ} 58^{\prime} \mathrm{N}, 1^{\circ} 30^{\prime} \mathrm{W}, 990\right.$ $\mathrm{m}$ above sea level) is one of the main staging and wintering areas of the western European population of common cranes (Alonso et al. 1986, Alonso and Alonso 1988). It consists of a basin of around 53,000 ha surrounding a saline lake with a water surface of approximately $1,400 \mathrm{ha}$. During our study, most of the land was intensively cultivated $(28,712 \mathrm{ha})$, mainly with wheat and barley, and some sunflower. Cranes arrived at Gallocanta during October-November. A variable fraction of the birds remained there throughout the winter, and left the area in Feb- 
ruary-March. Most of the other birds continued migration to their traditional wintering areas in the southwestern Iberian Peninsula (Alonso et al. $1990 a$ ).

\section{METHODS}

\section{Crane Censuses}

Before 1979, the crane population using Gallocanta was surveyed on a weekly to biweekly basis (Hernández 1986). Beginning in 1979, we or the guards at the lake area counted the birds 1-2 times/week. Two to 6 observers counted cranes that left the roosts in early morning and entered them the previous or following evening.

Several authors have called attention to the pitfalls of using temporally related observations, mainly by underestimating variance or artificially increasing sample size (e.g., Raveh and Tapiero 1980, Swihart and Slade 1985, Burt et al. 1988). Although most studies assume or demonstrate no temporal relationships between observations, in others, estimation of these relationships may indeed constitute the main objective (e.g., Sauer and Boyce 1979, Garsd and Howard 1981, Boyce and Miller 1985, Aebischer 1990). We used the biweekly average figures for number of birds and food availability as independent data in our time series analysis. Because the study area is mainly a staging area during migration, and most non-wintering birds usually spend less than 2 weeks there (Alonso et al. $1990 \mathrm{~b}$ ), use of data separated by longer time periods would result in a loss of information during peak passage periods or when food conditions changed rapidly as a consequence of intensive farming activity and depletion. Also, interannual variations in migration phenology or food availability exceed 15 days. Moreover, it has been suggested that relationships between bird numbers and food availability are best studied using several data points per season (e.g., Goss-Custard and Charman 1976, Inglis et al. 1990). Therefore, we used 13 data points/winter season, 1 for each of the 13 2-week intervals between early. October and mid-April, which comprised the potential wintering period of the cranes. The gaps between years did not affect the model, because the conditions experienced by the cranes at the breeding areas, $3,000 \mathrm{~km}$ north of our study area, were much less relevant for the number of cranes using Gallocanta than local ecological conditions.

\section{Food Availability Estimation}

When cranes arrive in October-November, only a small percentage of fields are sown, with the rest left as stubble fields. Cranes then feed almost exclusively on cereal grain spilled during harvest, and also take waste sunflower seeds from the few sunflower stubble fields present (Alonso et al. 1984). Both plowing of stubble and depletion of cereal grain by the cranes cause a decrease in food availability throughout the winter, which is only slightly compensated by the newly sown fields. The sown cereal is then used by the cranes as an alternative food source. In years with normal precipitation, plowing of stubble fields occurs gradually during the winter; whereas there are 2 peaks in sowing activity in late October and late February. In contrast, much plowing is delayed in dry years until February, which maintains high food availability on stubble fields during midwinter months. No other bird or mammal species feeds on sown cereal, nor has a significant effect on the depletion of waste cereal on stubble. Only a few $(<100)$ greylag geese (Anser anser) and ducks (Anas spp., a few hundred) spend the winter in our study area. Numbers of common coots ( $F u$ lica atra) and diving ducks vary between a few hundred to several thousand, but they do not consume cereal or sunflower seeds. Thus, the amount of seeds on cereal and sunflower stubble and sown ground should provide an accurate measure of food availability for cranes.

Every 2 weeks, from 1981 to 1990 , we sampled the percentages of cereal stubble fields and sown ground from a $70-\mathrm{km}$ randomly selected transect of 930 farms on the study area. Between 1987 and 1990 , we also counted the waste grain on 20 quadrats of $25 \times 25 \mathrm{~cm}$ in 72 cereal stubble fields and on 20 quadrats of $50 \times 50 \mathrm{~cm}$ in 0-10 (depending on yearly availability) sunflower stubble fields, selected randomly along this transect. The seasonal depletion curves obtained from this analysis were applied to previous years. The number of seeds counted on stubble fields were transformed to mass figures to provide an estimate of the food availability every 2 weeks.

Since direct measurements were not available for the period 1970-80, we estimated the food availability then by assuming: a loss of $5 \%$ of the cereal grain during harvest in July (Díaz 1986); a 5\% decrease of the cereal grain harvest between July and October, due mainly to sheep 
grazing, equal to the measured average for the period 1980-90; and a regression for plowing activity, with the amount of precipitation in each year (normal vs. dry yr) as a covariable.

Our first assumption ignored the interannual variability in harvest loss due to factors such as height of cereal, state of ground during harvest, etc. However, because changes in food availability depend mainly on the decrease in the stubble surface due to plowing rather than on yearly variability in the amount of waste cereal on individual stubble fields, a value of 5\% loss during harvest was probably a reasonable estimate for our purposes. To calculate the regression, the threshold precipitation value between normal and dry years was set at $25 \mathrm{~mL} / \mathrm{m}^{2}$ between September and October, based on comparison of plowing activity and rainfall figures during 1981-90 and inquiries to local farmers.

Cranes preferred fields recently sown and did not usually forage on sprouted cereal. Because cranes have to dig out seeds, we assumed $5 \%$ of the cereal sown as a realistic food availability estimate for all sown grounds in our study area. This figure was the maximum sown seed consumption according to our direct field measurements (Alonso et al. 1987).

Finally, we estimated food availability at other wintering areas in the Iberian Peninsula. Acorns of holm oaks (Quercus rotundifolia) constitute the main food of common cranes at their traditional wintering areas in southwestern Spain (Soriguer and Herrera 1978, Alonso et al. 1989). We used published information on annual figures for surface and acorn crop figures for the period 1973-86 (Minist. Agric. Pesca Alimentación 1987). These data were compared with the seasonal mean and winter minimum numbers of common cranes using Gallocanta each year.

\section{Influence of Hunting}

Although common cranes are legally protected in Spain, hunting of ducks affected the behavior of the cranes at feeding and especially at roosting sites in the lake. Duck hunters had access to the lake 2 days/week until 1973. A restricted hunting area was established that year, including the lake and its surroundings $(6,492$ ha), limiting duck hunting to 4 days/winter. Beginning in 1981, all hunting was prohibited, and finally the area was declared a national wildlife refuge in 1985 . Cranes were very sen- sitive to disturbances caused by duck hunting activities, and easily abandoned roosts located close to hunters. Thus, the effect of duck hunting was more qualitative than quantitative, with presence or absence of hunting being much more important than the number of hunters, hunting days, or the hunting bag. Qualitative variables generally are used in such situations (Starfield and Bleloch 1986). We quantified the influence of hunting activity by means of 2 binary variables ( 0 before the hypothesized effect, and 1 after). The first variable delineated 2 hunting days/week (value 0 until 1973) versus 4 hunting days/winter (value 1 from 1973). The second variable accounted for presence/absence of all hunting (respectively, value 0 until 1981, and value 1 from 1981).

\section{Statistical Procedures}

There is no consensus on the best technique for standardizing migration count data for avian trend studies, although a variety of methods have been used (Bednarz et al. 1990, Titus and Fuller 1990). We used Box-Jenkins Time Series Analysis (Box and Jenkins 1976, Abraham and Ledolter 1983) because it enabled us to study the influence of various factors on crane numbers after removing the cyclic structure and/or the linear trend from the series of crane censuses. We applied a logarithmic transformation $\ln Y_{t}\left(Y_{t}\right.$ is the number of cranes at 2-week interval $t$ ) to achieve a homoscedastic distribution. Linear trend of the mean was eliminated by applying a first order difference $\nabla \ln Y_{t}=(1-$ B) $\ln Y_{t}=\ln Y_{t}-\ln Y_{t-1}$, where $\nabla=1-B$ is the backward difference operator; $B$ is the backshift operator and operates on the observation $Y_{t}$ by shifting it 1 point back in time. Thus, $B\left(Y_{t}\right)$ $=Y_{t-1}$. In general, $B^{k}\left(Y_{t}\right)=Y_{t-k}$. The autocorrelation function of $\nabla \ln Y_{t}$ indicated nonstationarity with respect to the seasonality of the series and suggested that further seasonal differencing was needed. This differencing is expressed as $\nabla_{13} \ln Y_{t}=\left[\ln Y_{t}-\ln Y_{t-1}\right]-[\ln$ $\left.Y_{t-13}-\ln Y_{t-14}\right]$.

This function contained no obvious trends, suggesting that the transformed and differenced series $y_{t}=\nabla_{13} \ln Y_{t}$ were stationary. The next step was to arrive at an initial guess of the seasonal and nonseasonal autoregressive and moving average structure needed to explain the autocorrelation function of $y_{t}$. The autocorrelation functions of autoregressive-moving average 
models (ARIMA models) are characterized by a discrete number of spikes corresponding to the moving average part of the model, and damped exponentials and/or damped sinewaves corresponding to the autoregressive part of the model. We used the sample and partial autocorrelation function to identify autoregressive and/or moving average terms, minimizing the number of terms included in the model. Later, we estimated the parameters and checked the adequate fitting of the model. An initial model was $y_{t}=(1-\theta B)(1-\theta B) a_{t}$, where we initially estimated parameters $\theta$ and $\theta$, using a procedure described by Box and Jenkins (1976) and available in BMDP software (Dixon 1990). Both Chisquare and Kolmogorov-Smirnov tests were used to check normality of the residuals. The LjungBox portmanteau Q-statistic (Ljung and Box 1978) was applied to show the absence of significant autocorrelation among the first 20 autocorrelation coefficients of the residuals.

After fitting the univariate model for the number of birds, we studied the relationship between it and food availability by calculating the crosscorrelation function. This function measures the relationship between the predictor series (food availability) at time $t$ and the predicted series (numbers of cranes) at time $t+k$, where $k$ is the interval between observations $(k$ $=0,1,2, \ldots)$. However, food availability also was an autocorrelated series. Therefore, we removed autocorrelation from the food availability series before calculating crosscorrelation (McCleary and Hay 1980). We adjusted a model to the transformed and differenced series $x_{t}=$ $\nabla \nabla_{13} \ln X_{t}$, where $X_{t}$ represented the amount of food available biweekly, $t$. Residuals of the model adjusted to $x_{t}$ and residuals of the univariated model adjusted to the series $y_{t}$ were used to calculate the crosscorrelation function.

Later, to study this relationship during the period of lowest food availability, we calculated crosscorrelation with a subsample of the model that only included the midwinter months (Dec and Jan). We used data from winters 1981-90, which were measured directly in the field.

Finally, we analyzed the influence of hunting by adding an intervention function (Box and Tiao 1975) accounting for partial and complete protection of the study area. The function was:

$$
y_{t}=\nu(B) R H_{t}+\nu(B) P H_{t}+\theta(B) a_{t}
$$

where $y_{t}=\nabla_{13} \ln Y_{t}$. The terms $\nu(B) R H_{t}$ and
$\nu(B) P H_{t}$ represent interventions of restricted and prohibited duck hunting, respectively. The term $\theta(B) a_{t}$ represents the moving average model. Following McCleary and Hay (1980), the intervention function was defined as:

$$
\nu(B)=\frac{\omega(B)}{\delta(B)}=\frac{\omega_{0}+\omega_{1} B+\ldots+\omega_{s} B^{s}}{1-\delta_{1} B-\ldots-\delta_{r} B^{r}}
$$

where $\omega(B)$ reflects the change in the level of the postintervention series; $s$ is the time elapsed until the intervention is complete; $\delta(B)$ expresses the rate at which the series approaches its asymptotic postintervention level. Small values of $\delta_{r}$ indicate rapid stabilization; whereas large values indicate that many observations will be necessary for the asymptotic level to be reached. Restriction and prohibition of hunting were absolute and permanent measures, and thus the term $\omega(B)$ was reduced to $\omega_{0}$. However, the response of the crane population using our study area to such protection measures was gradual and permanent. Therefore, the form of the term $\delta(B)$ was simplified to $1-\delta_{1}(B)$ (see McCleary and Hay 1980). Substituting the new values of $\omega(B)$ and $\delta(B)$ in $\nu(B)$, we obtained:

$$
y_{t}=\frac{\omega_{0}}{1-\delta_{1} B} R H_{t}+\frac{\omega_{0}}{1-\delta_{1} B} P H_{t}+\theta(B) a_{t}
$$

where we estimated the parameters of both hunting restriction steps and moving average term simultaneously.

Data available on oak wood surface and acorn productivity at other wintering areas in southwestern Spain were yearly figures. These series also were log-transformed and differenced to achieve stationarity. Later, we calculated crosscorrelations with annual mean and winter minimum figures for numbers of cranes in our study area.

\section{RESULTS \\ Crane Numbers}

The number of cranes using Gallocanta increased throughout the 20 years of study. Cranes were not a regular staging or wintering species between 1970 and 1973, although they were regularly observed at the study area during both migrations. The bimodal yearly pattern reflects the higher crane numbers during both migration periods rather than in midwinter. There were important interannual variations in both 


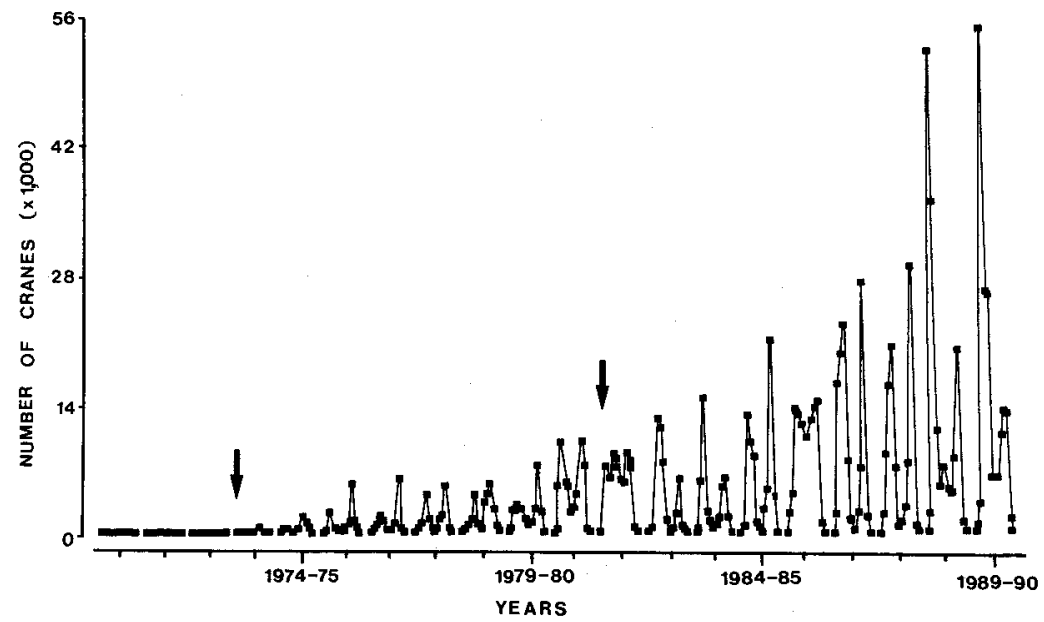

Fig. 1. Biweekly variation in the number of common cranes staging at Gallocanta, Spain, October 1970-April 1990. The left arrow indicates the restriction from 2 duck hunting days/week to only 4 hunting days/winter. The right arrow indicates total prohibition of duck hunting.

peak numbers and staging phenology (Fig. 1). The absence of damped exponentials and/or sinewaves in the sample and partial autocorrelation functions indicated that there were no autoregressive terms to include in the model. With these data, we tentatively identified an $\operatorname{ARIMA}(0,1,1)(0,1,1)_{13}$ model for predicting crane numbers. The partial autocorrelation function of the differenced series helps confirm our choice of a pure moving average model. There were several significant partial correlations, implying that an autoregressive model for this series would require more than 2 parameters. Thus, we used an $\operatorname{ARIMA}(0,1,1)(0,1,1)_{13}$ model, which was more parsimonious (Liu 1988). The model fitted was:

$$
\begin{aligned}
y_{t}= & \left(1-0.3520 B-0.3912 B^{2}\right) \\
& \left(1-0.5103 B^{13}\right) a_{t}
\end{aligned}
$$

where the 3 coefficients were significant $(t$-ratios were $5.23,5.88$, and 8.95 , respectively; all $P<$ 0.01 ). This model accounted for migratory fluctuations in crane numbers and for the relationship between 2 consecutive censuses. It estimated the number of cranes at any time using the counts from the previous 2 weeks of the same year and from the same 2 weeks of the previous year. This predictive relation might appear trivial, but it should be stressed that our study focused on the errors in the model predictions, i.e., the residuals. Although there was no temporal structure in the first 20 autocorrelation coefficients of the residuals $\left(Q_{20}=15.18\right.$,
$P>0.05)$, the latter did not show a normal distribution $\left(\chi_{8}^{2}=90.91, P<0.001\right.$; Kolmogorov-Smirnov $D_{8}=0.14, P<0.01$ ), indicating that there was still some information not accounted for by this model.

\section{Effect of Food Availability and Hunting}

Food availability also changed between years, but did not show a clear increasing or decreasing tendency (Fig. 2). Peak food values during the winter season $1985-86$ were due to large amounts of cereal grain on stubble fields as a consequence of a hailstorm just before harvesting. The model adjusted to the series of food availability $x_{t}$ was

$$
x_{t}=(1-0.1928 B)\left(1+0.8666 B_{13}\right) a_{t}
$$

where $x_{t}=\nabla_{13} \ln X_{t}$; coefficients were significant ( $t$-ratios were 2.61 and 28.45 , respectively, all $P<0.01$ ). There was no temporal structure in the first 20 autocorrelation coefficients of the residuals $\left(Q_{20}=20.86, P>0.05\right)$, and the residuals were normally distributed $\left(\chi_{8}^{2}=10.29\right.$, $P>0.05$; Kolmogorov-Smirnov $D_{8}=0.06, P>$ 0.05 ). The residuals of the univariate model of crane numbers were not correlated with those of the food availability model for any lag applied, indicating that the food availability was not a limiting factor. However, considering only midwinter data (Dec-Jan), residuals of the crane numbers model were crosscorrelated with those of the food availability model only in the same 2-week period ( $r=0.36,35 \mathrm{df}, P<0.05$ ). All 


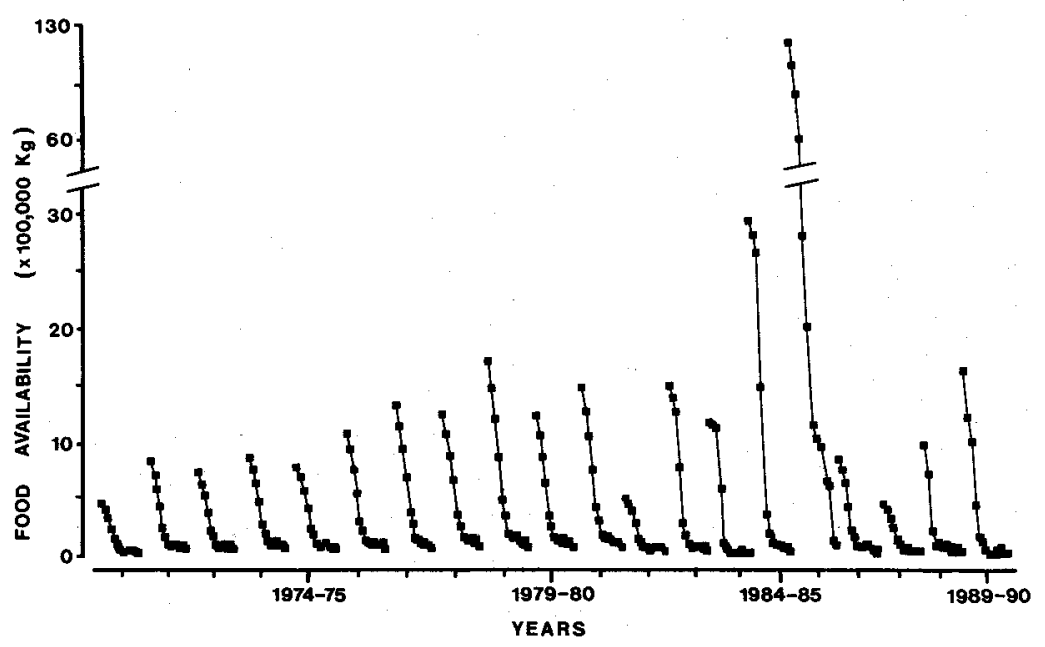

Fig. 2. Biweekly variation in food availability at Gallocanta, Spain, October 1970-April 1990. In 1985, a hailstorm just before harvesting produced an exceptionally high availability of waste grain on cereal stubble.

other crosscorrelation coefficients were not significant.

The addition of the interventions for hunting restriction and hunting prohibition improved the model:

$$
\begin{aligned}
y_{t}= & \frac{0.937}{1-0.839 B} R H_{t}+\frac{0.459}{1-0.824 B} P H_{t} \\
& +\left(1-0.279 B-0.446 B^{2}\right)\left(1-0.532 B^{13}\right) a_{t}
\end{aligned}
$$

where $t$-ratios were 2.34 and 1.22 for coefficients of $\omega_{0}$ (restricted and prohibited hunting, respectively $R H_{t}$ and $\left.P H_{t}\right), 10.17$ and 4.85 for coefficients of $\delta_{0}$ (restricted and prohibited hunting, respectively), and 4.20,6.80 and 9.39 for coefficients of the univariate model $(P<0.05)$. Predictions of the univariate model after incorporating both interventions produced normally distributed residuals $\left(\chi_{B}^{2}=14.35, P>0.05\right.$; Kolmogorov-Smirnoff $\mathrm{D}_{8}=0.06, P>0.05$ ), and autocorrelation coefficients without structure, indicating that the model fitting process was finished. The model explained $91 \%$ of the variance of crane censuses (Fig. 3).

\section{Other Factors}

During the last 2 decades there has been no significant decrease in the acorn production at other traditional wintering areas of southwestern Spain (Pérez 1988), in spite of the conversion of a relatively small percentage surface of holm oak woods into irrigated farmland. Crane numbers have even increased at some of these converted areas, benefiting from new food re- sources provided by farming (Alonso et al. 1987, Alonso et al. 1990a). Also, some holm oak areas apparently suitable for cranes are not used by the birds. The series of holm oak wood surface area and acorn productivity, and those of mean and minimum annual censuses of wintering cranes, did not show autocorrelation once transformed to stationary series. Crosscorrelation between these series was not significant for any lag values. We concluded that possible changes in the acorn productivity at other wintering areas in Spain had no significant effect on the use of Gallocanta.

\section{DISCUSSION}

Our results suggest that hunting restrictions were the main factor determining the increase observed in numbers of common cranes using Gallocanta as a staging and wintering area. Both steps of protection, the reduction in the number of duck hunting days established in 1973, and the prohibition of duck hunting in 1981, had a significant effect on the crane population increase. The absence of a correlation between the 20-year series of crane counts and food availability suggests that food was not an important factor determining interannual changes in the number of birds during our study period. Larger food quantities than those required by the staging population were probably already available at the beginning of the study period ( 2 decades ago), and it seems that current autumn peak numbers have not yet reached the carrying capacity of the area. When cranes arrive in our study area in autumn, they find a large food 


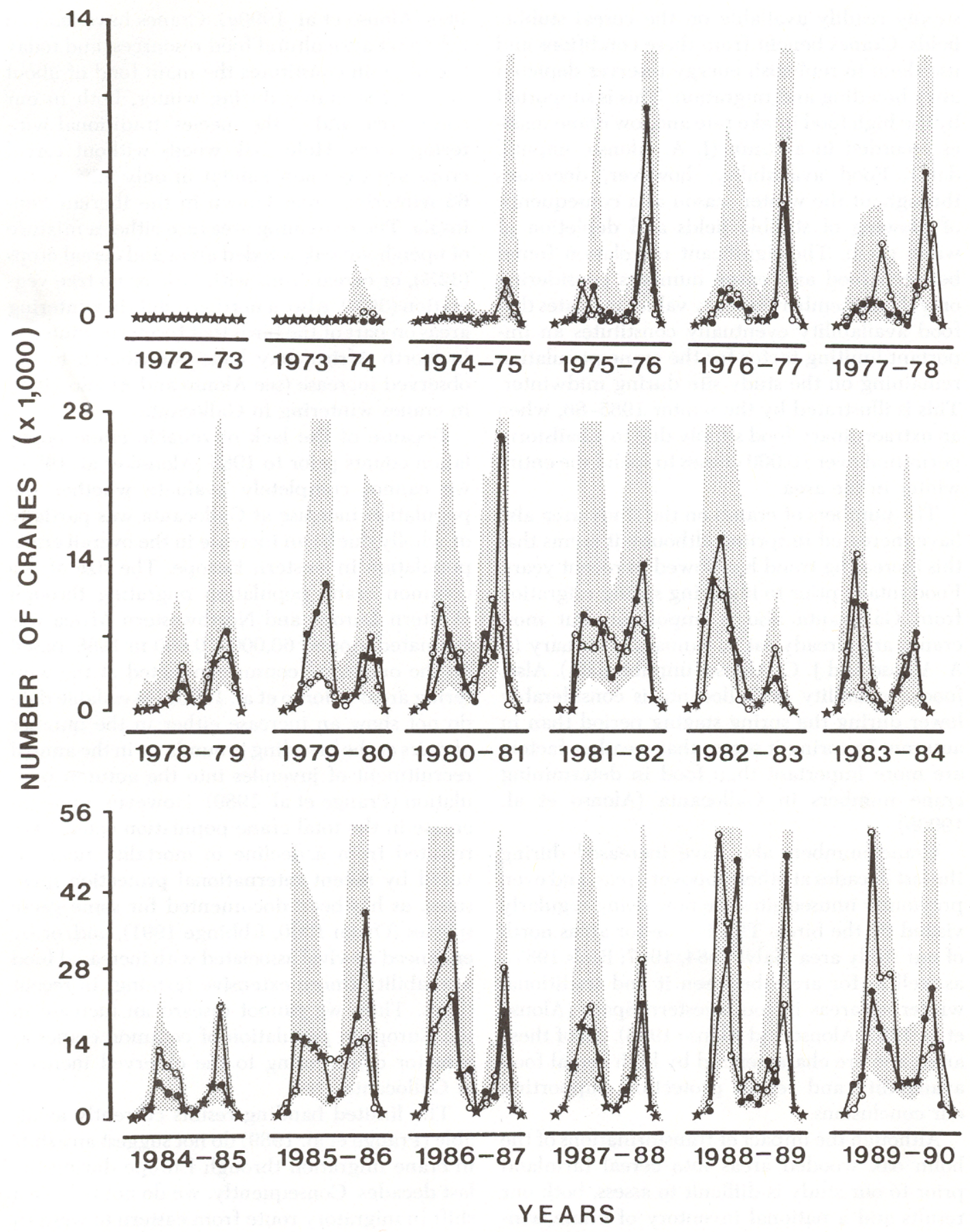

Fig. 3. Numbers of cranes predicted by the model (closed circles) and surveyed (open circles) biweekly between 1972 and 1990. Stars indicate overlap between open and closed circles. Shaded areas indicate the $95 \%$ confidence limits. Note differences in vertical scales. 
supply readily available on the cereal stubble fields. Cranes benefit from these conditions and use them to replenish energy reserves depleted after breeding and migration. This is supported by the high food intake rate and low crane masses recorded in autumn (J. A. Alonso, unpubl. data). Food availability, however, decreases throughout the winter season as a consequence of plowing of stubble fields and depletion of waste grain. The significant correlation found between food and crane numbers considering only the December-January values indicates that food availability eventually constitutes an important limiting factor for the crane population remaining on the study site during midwinter. This is illustrated by the winter 1985-86, when an extraordinary food supply due to a hailstorm permitted over 10,000 cranes to spend the entire winter in the area.

The numbers of cranes on the study area also have increased in spring, although it seems that this increasing trend has slowed in recent years. Food intake prior to initiating spring migration from Gallocanta also is important, but most cranes are already fat in January-February ( $\mathrm{J}$. A. Alonso and J. C. Alonso, unpubl. data). Also, food availability at Gallocanta is considerably lower during the spring staging period than in autumn. In spring it seems that weather factors are more important than food in determining crane numbers in Gallocanta (Alonso et al. 1990b).

Crane numbers also have increased during the last decades at other stopover areas, and even previously unused sites are now being regularly visited by the birds. This is true for areas north of our study area (Salvi 1984, 1987; Riols 1987), as well as for areas between it and traditional wintering areas in southwestern Spain (Alonso et al. 1987, Alonso and Alonso 1988). All of these areas also are characterized by high cereal food availability and recent protection, supporting our conclusions.

Although the impact of transformations of the holm oak wooded areas into cereal farmland prior to our study is difficult to assess, both our results and a national inventory of crane wintering areas (Alonso et al. 1990a) suggest that these detrimental habitat changes elsewhere were not the primary cause of the increased use of Gallocanta. Indeed, conversion of holm oak woodland to cereal farmland has probably produced the opposite effect of increasing or concentrating birds. This increase has been observed at some particularly well documented sites (Alonso et al. 1990a). Cranes have learned to exploit agricultural food resources, and today cereal grain constitutes the main food of about $40 \%$ of the cranes during winter, both in our study area, and at the species' traditional wintering areas. Holm oak woods without cereal crops are the main habitat in only $32 \%$ of the 63 wintering areas known in the Iberian Peninsula. The remaining areas are either a mixture of open holm oak wooded areas and cereal crops $(32 \%)$, or cereal crops with little or no tree vegetation (36\%). Also, a northern shift in wintering areas on part of the birds that formerly wintered in North Africa may have contributed to the observed increase (see Alonso and Alonso 1988) in cranes wintering in Gallocanta.

Because of the lack of reliable crane population counts prior to 1985 (Alonso et al. 1986), we cannot completely evaluate whether the population increase at Gallocanta was partially or wholly due to an increase in the overall crane population in western Europe. The size of the common crane population migrating through Western Europe and Northwestern Africa was estimated around 60,000-70,000 in 1988, based on the only total census conducted at the wintering areas (Alonso et al. 1990a). Available data do not show an increase either in the number of pairs at the breeding grounds, or in the annual recruitment of juveniles into the autumn population (Prange et al. 1989). However, some increase in the total crane population could have resulted from a decline in mortality rates favored by recent international protection measures, as has been documented for some geese species (Owen 1990, Ebbinge 1991), and/or by enhanced survival associated with increased food availability (more extensive farming) in recent times. Thus, we cannot discard an increase in the European population of common cranes as a factor contributing to the observed increase at Gallocanta.

The limited banding results currently available (Prange et al. 1989) do not suggest any shift in crane migration through Europe during the last decades. Consequently, we do not believe a shift in migratory route from eastern to western Europe is responsible for the increase in wintering cranes at Gallocanta.

\section{RESEARCH AND MANAGEMENT IMPLICATIONS}

The Box-Jenkins Time Series Analysis made it possible to integrate seasonal and interannual changes in the same model by removing the 
bimodal pattern characteristic of a staging area that is occupied during both migrations. The model obtained may be used to predict future trends in the crane population staging in the study area.

Because food availability did not limit the size of the crane population staging during migration prior to this time, we believe that the most immediate factor affecting the observed increase in use of Gallocanta by common cranes was the restriction in duck hunting activities in 1973. This trend was later reinforced by the total protection of the area in 1981. Cranes probably would have used Gallocanta much earlier if hunting pressure had been eliminated. Since a comparable decrease in numbers at other traditional wintering areas in Spain has not been observed, we suggest that a decline in mortality rates due to legal protection measures along the migratory route and a possible shift north of the wintering range due to feeding opportunities provided by recent agricultural practices may have enabled crane numbers to increase at $\mathrm{Ga}$ llocanta over the long term.

\section{LITERATURE CITED}

Abraham, B., AND J. Ledolter. 1983. Statistical methods for forecasting. John Wiley and Sons, New York, N.Y. 367pp.

AEBISCHER, N. J. 1990. Assessing pesticide effects on non-target invertebrates using long-term monitoring and time-series modelling. Functional Ecol. 4:369-373.

Alonso, J. A., AND J. C. Alonso. 1988. Invernada de la Grulla Común Grus grus en la Península Ibérica. Pages 123-136 in J. L. Telleria, ed. Invernada de aves en la Península Ibérica. Soc. Española Ornitol., Madrid.

$\longrightarrow$, AND R. MuNoz-Pulido. $1990 a$. Areas de invernada de la Grulla Común (Grus grus) en España. Pages 7-161 in J. A. Alonso and J. C. Alonso, eds. Demografía e Invernada de la Grulla Común en España. ICONA, Madrid.

,$- \longrightarrow$, AND J. VEIGA. 1984. Winter feeding ecology of the crane in cereal farmland at Gallocanta, Spain. Wildfowl 35:119-131.

- , H. Prange, And J. C. Alonso. 1989. Ernährung. Pages 95-99 in H. Prange, ed. Der graue kranich. A. Ziemsen Verlag, Wittenberg-Lutherstadt.

Alonso, J. C., J. A. Alonso, and F. J. Cantos. 1986. On the size of the common crane (Grus grus) population migrating through Western Europe. Ornis Fennica 63:58-59.

- $\longrightarrow$, AND L. M. BAUTISTA. $1990 \mathrm{~b}$. Crane Grus grus migration over Gallocanta, Spain. I) Daily variations in migration volume. Ardea 78:379-388.

, J. P. Veiga, AND J. A. Alonso. 1987. Possible effects of recent agricultural development on the wintering and migratory pattern of common crane in Iberia. Pages 277-299 in G. W. Archibald and R. F. Pasquier, eds. Proceedings III International Crane Workshop. Int. Crane Found., Baraboo, Wis.

Bednarz, J. C., D. KLEM, JR., L. J. GoOdRich, AND S. E. SENNER. 1990. Migration counts of raptors at Hawk Mountain, Pennsylvania, as indicators of population trends, 1934-1986. Auk 107:96109.

Box, G. E. P., AND G. M. Jenkins. 1976. Time series analysis: forecasting and control. Second ed. Holden-Day, San Francisco, Calif. 350pp.

- AND G. C. TIAO. 1975. Intervention analysis with application to economic and environmental problems. J. Am. Stat. Assoc. 70:70-79.

BOYCE, M. S., AND R. S. MILlER. 1985. Ten-year periodicity in whooping crane census. Auk 102: $658-660$.

Burt; A., W. Hunte, AND F. DUfresne. 1988. Identifying the time scale of temporal association. Can. J. Zool. 66:2090-2092.

Díaz, A. 1986. Régimen de cultivos en la cuenca de Gallocanta y tendencias. Problemática del peritaje de daños a la agricultura por grullas: metodología y casuística. Primeras jornadas sobre problemática y conservación de la Grulla Común Grus grus en areas de invernada en España. Daroca. Dep. de Agricultura, Ganadería y Montes. Diputación General de Aragón. 33pp.

DrXoN, W. J., editor. 1990. BMDP statistical software manual. Univ: California Press. 1385pp.

EBBINGE, B. S. 1985. Factors determining the population size of arctic-breeding geese wintering in Western Europe. Ardea 73:121-128.

- 1991. The impact of hunting on mortality rates and spatial distribution of geese wintering in the western palearctic. Ardea 79:197-210.

EDwards, T. C., D. H. RusCh, K. F. Abraham, aND M. GILlesPIE. 1989. Survivorship in Canada geese: costs and benefits to the use of traditional migratory routes and wintering sites. Symp. on Long Term Ecol. Stud. of Birds. Moscow, Id. 8pp.

Garsd, A., AND W. E. Howard. 1981. A 19-year study of microtine population fluctuations using time-series analysis. Ecology 62:930-937.

Goss-Custard, J. D., and K. Charman. 1976. Predicting how many wintering waterfowl an area can support. Wildfowl 27:157-158.

HeRnÁndez, F. 1986. Situación y evolución de la población invernante de la Grulla Común en Gallocanta. I. Jornadas sobre Problemática y Conservación de la Grulla Común Grus grus en Areas de Invernada en España. Daroca. Dep. de Agricultura, Ganadería y Montes. Diputación General de Aragón. 33pp.

Inglis, I. R., A. J. IsAaCson, R. J. P. THEARLe, AND N. J. WESTwOOD. 1990. The effects of changing agricultural practice upon woodpigeon $\mathrm{Co}$ lumba palumbus numbers. Ibis 132:262-272.

JaSSBY, A. D., AND T. M. PowelL. 1990. Detecting changes in ecological time series. Ecology 71 : 2044-2052.

Krapu, G. L., D. E. FACEy, E. K. Fritzell, aND D. H. JoHnSON. 1984. Habitat use by migrant sandhill cranes in Nebraska. J. Wildl. Manage. 48:407-417. 
LIU, L. 1988. Box-Jenkins time series analysis. Pages 429-482 in W. J. Dixon, ed. BMDP statistical software manual. Univ. California Press.

LJUNG, G. M., AND G. E. P. Box. 1978. On a measure of lack of fit in time series models. Biometrika 65:297-304.

MCCleary, R., AND R. A. HaY. 1980. Applied time series analysis for the social sciences. Sage Publ., Beverly Hills, Calif.

Ministerio de Agricultura, Pesca y AliMENTACIÓN. 1987. Anuario de estadística Agraria, 1973-1986. Secretaría General Técnica, Madrid. $567 \mathrm{pp}$.

OWEN, M. 1990. The damage-conservation interface illustrated by geese. Ibis 132:238-252.

PÉRZ, A. 1988. Cambios y problemática en la dehesa. Univ. de Extremadura, Cáceres: 181pp.

Prange, H., J. C. Alonso, J. A. Alonso, and W. MEwks. 1989. Reproduktion und Zusammensetzungder Population. Pages 89-95 in H. Prange, ed. Der Graue Kranich A. D. Ziemsen Verlag. Wittenberg-Lutherstadt.

RaveH, A., AND C, S. Tapiero. 1980. Periodicity, constancy, heterogeneity and the categories of qualitative time series. Ecology 61:715-719.

Riols, C. 1987. Wintering of common crane in France. Aquila 93:123-136.

SAlvi, A. 1984. La grue cendrée, Grus grus, en Lorraine. Analyse des observations hivernales dès 1967 à 1984. Ciconia 8:1-24.

. 1987. Crane, Grus grus, migration in France from autumn 1981 to spring 1984. Aquila 93: 107-114.

Sauer, J. R., AND M. S. Boyce. 1979. Time series analysis of the national elk refuge census. Pages 9-12 in M. S. Boyce, and L. Hayden-Wing, eds. North American elk. Univ. of Wyoming, Laramie.

Soriguer, R., AND C. M. Herrera. 1978. Análisis de dos contenidos estomacales de Grulla Común (Grus grus). Ardeola 24:217-219.

Starfield, A. M., AND A. L. Bleloch. 1986. Building models for conservation and wildlife management. Macmillan Inc., New York, N.Y. 253pp.

Sugden, L. G., R. G. Clark, E. J. Woodsworth, AND H. GREENWOOD. 1988. Use of cereal fields by foraging sandhill cranes in Saskatchewan. J. Appl. Ecol. 25:111-124.

Swihart, R. K., AND N. A. Slade. 1985. Testing for independence of observations in animal movements. Ecology 66:1176-1184.

TACHA, T. C., P. A. VoHS, AND G. C. Iverson. 1984. Migration routes of sandhill cranes from midcontinental North America. J. Wildl Manage: 48: 1028-1033.

TrTuS, K., AND M. R. Fuller. 1990. Recent trends in counts of migrant hawks from northeastern North America. J. Wildl: Manage. 54:463-470.

WIENS, J. A., AND R. F. JoHNSTON. 1977. Adaptative correlates of granivory in birds. Pages $301-$ 340 in J. Pinowski and S. C. Kendeigh, eds. Granivorous birds in ecosystems. Cambridge Univ. Press.

Received 15 July 1991. Accepted 21 January 1992. Associate Editor: Sauer. 